\title{
Development of new heparin-like compounds and other antithrombotic drugs and their interaction with vascular endothelial cells
}

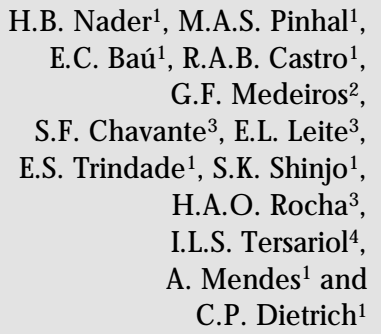

\author{
1D epartamento de Bioquímica, Escola Paulista de Medicina, \\ Universidade Federal de São Paulo, São Paulo, SP, Brasil \\ Departamentos de ${ }^{2} \mathrm{O}$ ceanografia, and ${ }^{3}$ Bioquímica, \\ Universidade Federal do Rio Grande do Norte, Natal, RN, Brasil \\ ${ }^{4}$ Centro de Investigação Bioquímica, Universidade de Mogi das Cruzes, \\ Mogi das Cruzes, SP, Brasil
}

\section{Correspondence \\ H.B. Nader \\ Departamento de Bioquímica EPM, UNIFESP \\ Rua 3 de Maio 100, 4 andar 04044-020 São Paulo, SP \\ Brasil \\ E-mail: hbnader.biog@epm.br \\ Presented at \\ SIMEC 2000 - International \\ Symposium on Extracellular \\ Matrix, Angra dos Reis, RJ, \\ Brazil, September 24-27, 2000. \\ Research supported by FAPESP, CNPq and CAPES}

Received January 26, 2001 Accepted March 28, 2001

\section{Abstract}

The anticlotting and antithrombotic activities of heparin, heparan sulfate, low molecular weight heparins, heparin and heparin-like compounds from various sources used in clinical practice or under development are briefly reviewed. Heparin isolated from shrimp mimics the pharmacological activities of low molecular weight heparins. A heparan sulfate from Artemia franciscana and a dermatan sulfate from tuna fish show a potent heparin cofactor II activity. A heparan sulfate derived from bovine pancreas has a potent antithrombotic activity in an arterial and venous thrombosis model with a negligible activity upon the serine proteases of the coagulation cascade. It is suggested that the antithrombotic activity of heparin and other antithrombotic agents is due at least in part to their action on endothelial cells stimulating the synthesis of an antithrombotic heparan sulfate.

\section{Sites of action of antithrombotic drugs}

The leading causes of death in the United States are diseases that involve heart and blood vessels, and as a consequence thrombosis (1). The incidence of death due to this cause is almost two times higher than the second, namely, cancer (Figure 1). This rate explains the current efforts to develop specific and potent antithrombotic agents.

The possible sites of action for antithrom-

\section{Key words}

- Heparin, anticlotting activity

- Heparan sulfate, antithrombotic activity

- Low molecular weight heparins, preparation and antithrombotic activity

- Antithrombotic agents, development for clinical use

- Crustacean heparin-like compounds, antithrombotic activity

- Antithrombotic agents

- Vascular endothelial cells botic compounds include blood itself, composed of plasma proteins and lipids, and cells. The red cells seem not to be a target for antithrombotic drugs, whereas white cells and platelets are intimately involved in thrombus formation.

The protease network in coagulation, fibrinolysis and the kallikrein-kinin system is shown in Figure 2. This cascade of events consists of a series of steps for the activation of serine proteases and modulation by specific inhibitors called serpins. The ultimate 


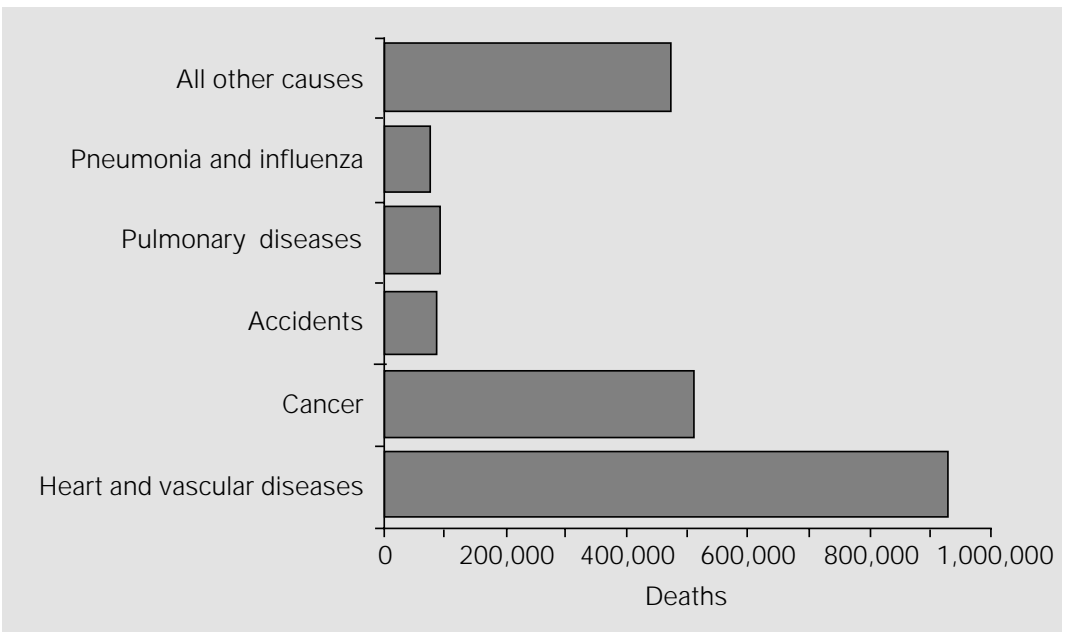

Figure 1. Causes of death in the US. Data from the American Heart Association (1993).

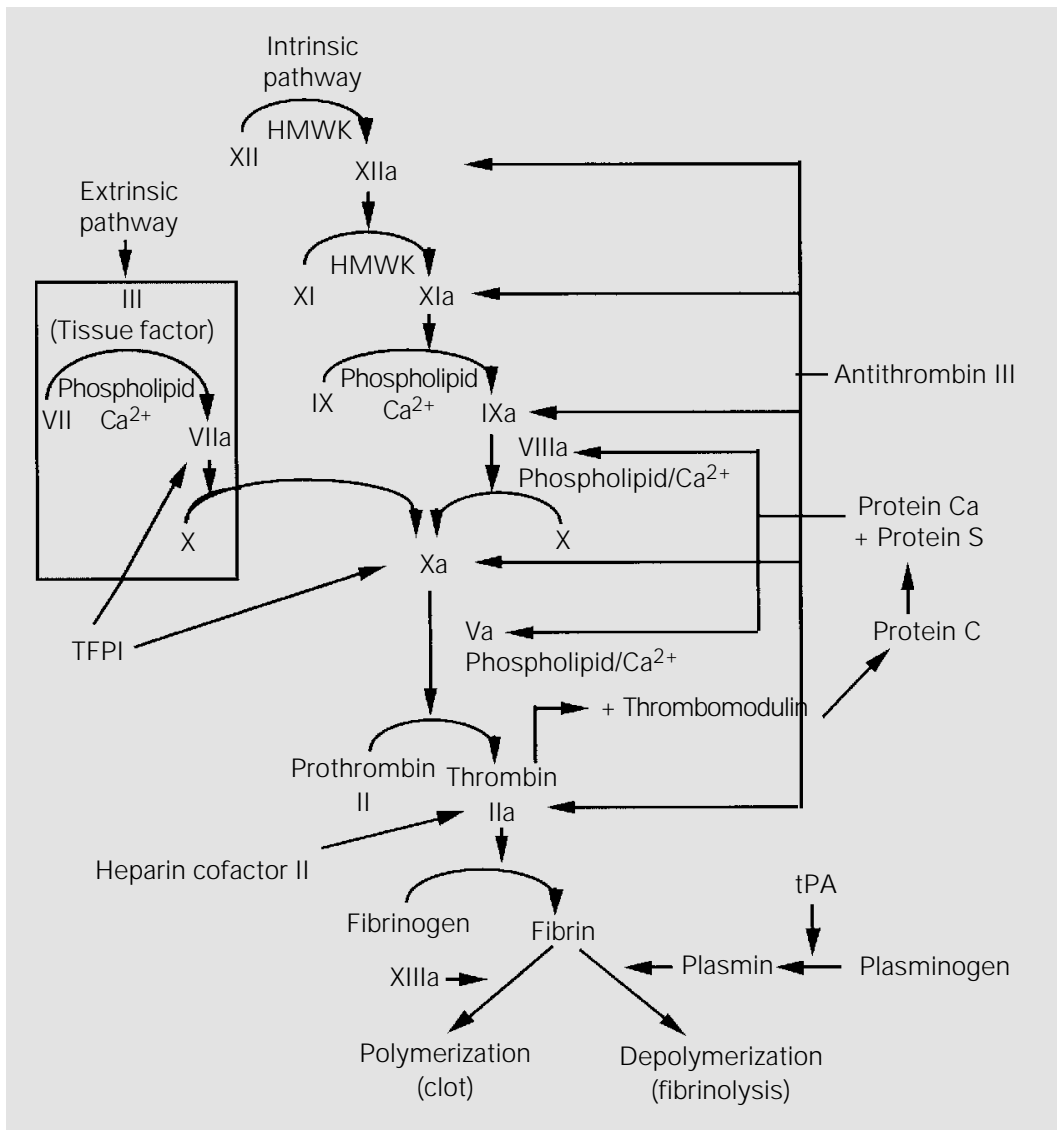

Figure 2. Coagulation cascade. HMWK, high molecular weight kininogen; TFPI, tissue factor pathway inhibitor; tPA, tissue plasminogen activator. goal of the coagulation system is the formation of clot that is the result of the limited proteolysis of a soluble protein from plasma (fibrinogen) into an insoluble protein (fibrin).

\section{Heparin: structure and mechanism of action}

Heparin was the first compound used as an anticoagulant and antithrombotic agent. Heparin was isolated by McLean in Canada in 1916 from a preparation of dog liver. The commercial heparin preparations, introduced in clinical practice 60 years ago, are from hog and bovine intestinal mucosa, as well as bovine lung. Chemical and enzymatic analyses and NMR spectroscopy revealed the main structural features of heparin. In our laboratory we have shown that heparin is mainly composed of a hexasaccharide containing iduronic acid 2-O-sulfate, glucosamine 2-6disulfate and non-sulfated glucuronic acid (2). This sequence is the main unit in the heparin molecule (Figure 3). Small variations occur among heparins from different sources.

Heparin acts as anticoagulant compound because it forms a ternary complex with antithrombin III and the different serine proteases of the coagulation cascade. The inhibition of thrombin by antithrombin is accelerated by more than 1,000 times in the presence of heparin. Heparin is also capable of potentiating the effect of another serpin called heparin cofactor II that is specific for thrombin. It also releases and increases the synthesis of the tissue factor pathway inhibitor by endothelial cells.

Some difficulties and side effects have been observed with the continuous clinical use of heparin, such as frequent activated partial thromboplastin time monitoring, variable anticoagulant effects, the inability to inhibit thrombin bound to the clot, and the occurrence of thrombocytopenia in some patients. 


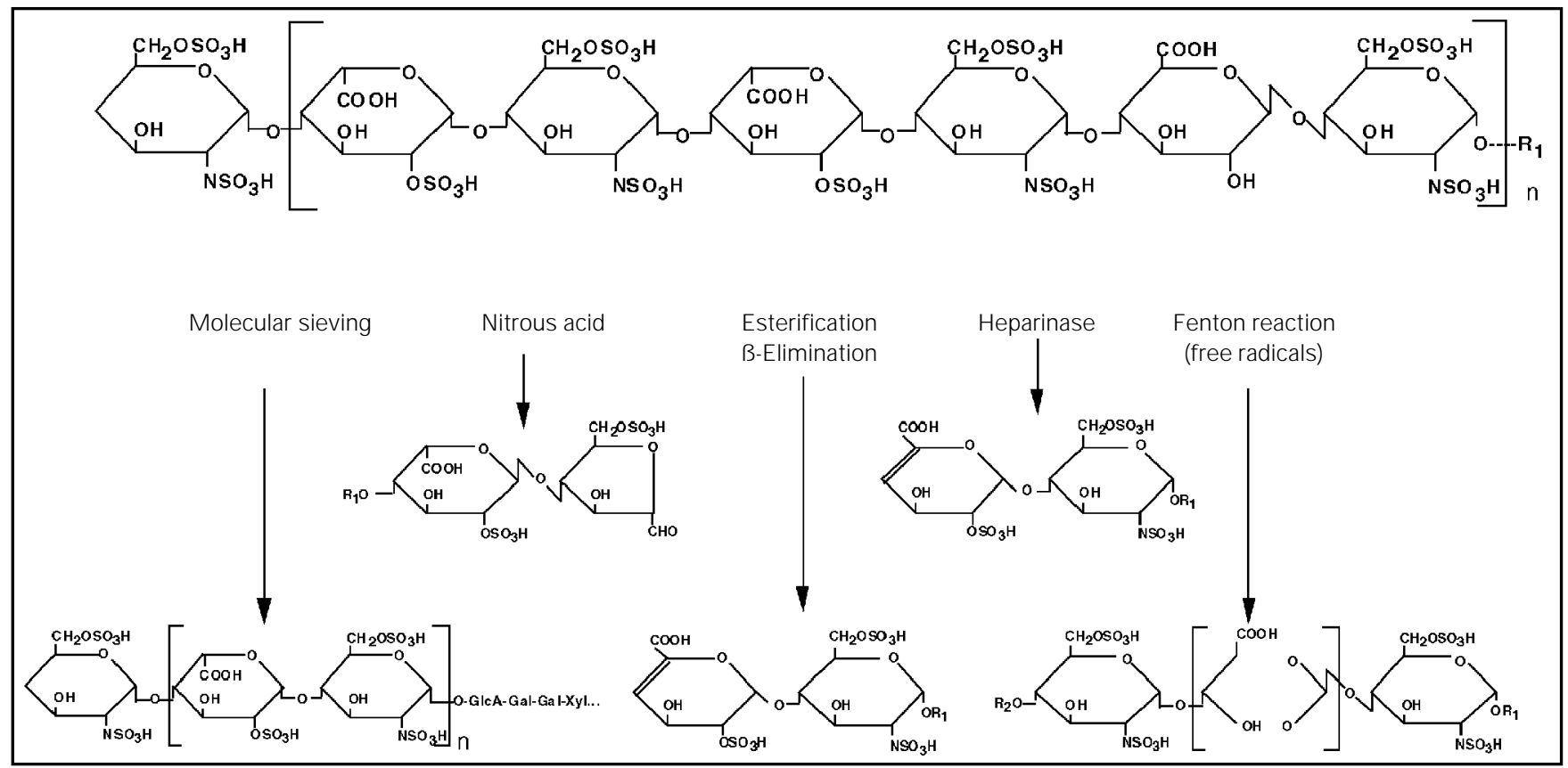

Figure 3. Methods of preparing low molecular weight heparins. Molecular sieving, gel filtration on Sephadex G-50 (29); nitrous acid, limited nitrous acid reaction (30); esterification and ß-elimination, benzylation and ß-elimination by a method developed by Aventis; heparinase, limited degradation with heparinase from Flavobacterium heparinum (2); Fenton reaction, oxidation with free radicals generated from $\mathrm{H}_{2} \mathrm{O}_{2}$ and $\mathrm{Cu}^{2+}(3)$.

\section{Antithrombotic activity of heparin fractions and heparin fragments prepared by chemical and enzymatic depolymerization}

By electrofocusing (3-5) it was possible to show that commercial heparin preparations are composed of molecules with different molecular masses ranging from 3 to 30 $\mathrm{kDa}$ (Figure 4). These different fractions were prepared on a large scale and those with high molecular mass were found to exhibit a potent anticoagulant effect in vitro, with values ranging from 200 to $300 \mathrm{IU} / \mathrm{mg}$, whereas molecules of $3 \mathrm{kDa}$ or less showed a negligible anticoagulant effect (around 10 $\mathrm{IU} / \mathrm{mg}$ ). In contrast, when these molecules were assayed in an in vivo model of thrombosis, both the high and low molecular weight (LMW) fractions were found to be potent antithrombotic drugs (Figure 4). Results of the in vivo model of thrombosis also showed that the different heparin preparations contain different proportions of high and LMW components, and this could account for the differences in clinical results.

Since the content of LMW heparins present in the heparin preparations with high in vivo antithrombotic activity accounts for only $5 \%$ of the commercial heparins, we decided to depolymerize heparin. Depolymerization was obtained by the Fenton reaction (3) that cleaves the heparin molecule in the glucuronic acid moieties, as well as by degradation with heparitinase II (6). Using these methods it was possible to produce LMW heparins in high yields, as shown by the electrofocusing profile of both standard and LMW heparin (Figure 5). When these LMW heparin fractions were tested in venous thrombosis models in vivo, namely, ligature of the vena cava, injection of kaolin into the mesenteric vein and injection of collagen into the femoral vein (6), they exhibited a more potent effect than standard heparin (Figure 6). Table 1 shows that the LMW heparins have a low anticoagulant effect in a whole plasma assay used to measure thrombin inhibition. Nevertheless, they exhibit potent anti- 
factor Xa activity, and also a dramatic effect on thrombus formation in vivo. Both standard heparin and LMW heparin bind to antithrombin, which has a binding site for thrombin and another for factor Xa. While standard heparin can modulate both sites, LMW heparin can interact only with the site for factor Xa, which explains its low anticoagulant activity and high anti-Xa activity in vitro.

These pioneering results led the pharmaceutical industries to search for different methods of heparin depolymerization in the eighties. Figure 3 shows the different commercially available heparins and the different methods for their preparation, namely, Fenton reaction (ardeparin and parnaparin), nitrous acid degradation (nadroparin and dalteparin), esterification and $\beta$-elimination (enoxaparin), heparinase (tinzaparin), and molecular sieving. The method of preparation produces structural differences between the commercial LMW heparins $(7,8)$ and, as a consequence, the Food and Drug Administration considers them different drugs. Three different LMW heparins are already commercialized in Brazil, e.g., enoxaparin (clexane), dalteparin (fragmin) and nadroparin (fraxiparina). In the last decade there was a tremendous increase in the sales of LMW heparins, reaching 2.5 billion dollars in 1999 compared to 150 million dollars of standard heparins. Examples of the use of LMW heparins have been reviewed (9-14).

\section{Antithrombotic activity of other heparin-like compounds}

Several other related compounds are being tested as antithrombotic agents. For instance, last year we isolated in high yields and characterized a heparin from the head of the Penaeus shrimp (15). So far, these tissues are of no commercial value since they are discards of the shrimp industry. When

Figure 4. Anticoagulant and antithrombotic activities of heparin fractions obtained by electrofocusing. A, Toluidine blue staining. B, Precipitated complexes of ampholine-heparin fractions photographed against a black background. Lanes 1 to 5, Pharmaceutical companies (1: Riker 2: Roche; 3: Wilson; 4: Lederle; 5, Upjohn). USP, United States Pharmacopea anticoagulant assay; MM, molecular mass.

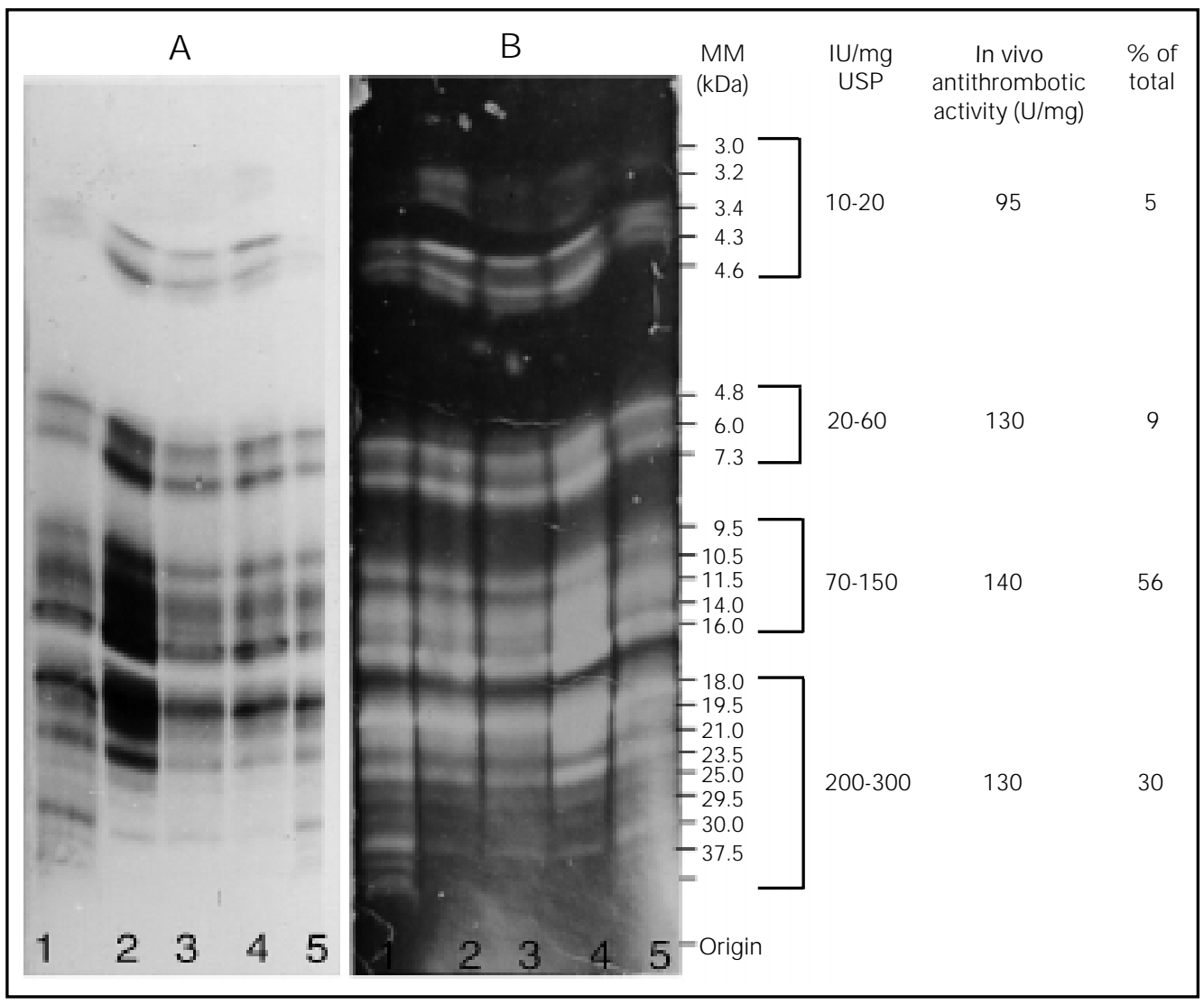


compared to standard heparin, this heparin shows a lower inhibition of thrombin and a similar effect on factor Xa (Figure 7A). The shrimp heparin also has a strong inhibitory effect on heparin cofactor II and a potent in vivo antithrombotic activity in rabbits (Table 2 ). Thus, the pharmacological profile of this heparin resembles that of the LMW heparins. The commercial appeal of this heparin is great, since in Europe heparin of bovine origin has been prohibited because of prion disease. Thus, at present the only commercial source is hog mucosa. Furthermore, this heparin, without any chemical depolymerization introducing new elements in its molecule, is perhaps a safer drug when compared to the other LMW heparins. This heparin is now being prepared in large amounts for experiments on monkeys and man.

Another interesting compound is the heparan sulfate from bovine pancreas. This compound is a better antithrombotic agent in a rat model of venous thrombosis (16) than standard and LMW heparins (Figure 6). Chondroitin sulfate from cartilage and dermatan sulfate from pig skin show no effect. When tested in a guinea pig arterial thrombosis model (17), pancreatic heparan sulfate also showed a potent inhibitory effect comparable to heparin (Figure 8). It should be mentioned that the type of thrombus is different in arterial and venous vessels. The arterial thrombus is mainly due to the aggregation of platelets, whereas the venous thrombus is related to fibrin deposition. This heparan sulfate has no effect on AT-III-mediated inhibition of serine proteases. Curiously, a heparan sulfate prepared from bovine lung has low antithrombotic activity.

Heparan sulfate from bovine pancreas has little effect on heparin cofactor II. On the other hand, heparan sulfate from the crustacean Artemia franciscana is a potent modulator of heparin cofactor II (18), as also are dermatan sulfate from bovine pancreas and heparin (Figure 7B).

Another dermatan sulfate extracted from

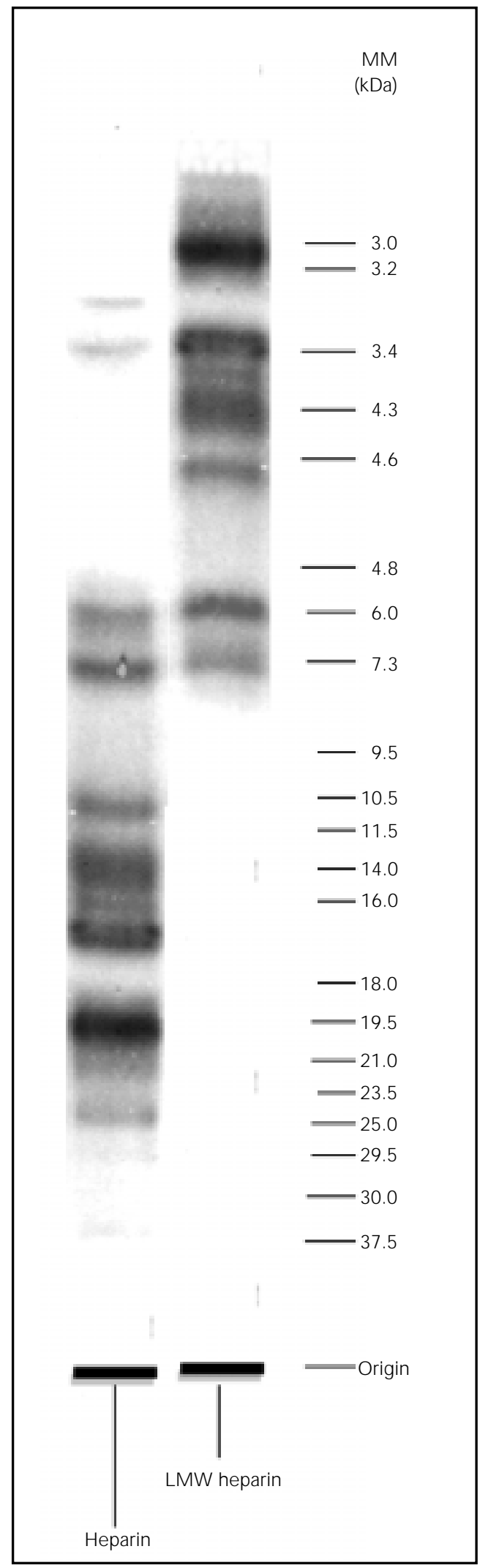

Figure 5. Electrofocusing of heparin and low molecular weight (LMW) heparin prepared by the Fenton reaction. The molecular masses (MM) of standards are given in $\mathrm{kDa}$ on the right side of the figure. 
Figure 6. In vivo antithrombotic activities of heparin, low molecular weight (LMW) heparins, heparan sulfate and other glycosaminoglycans in different venous models. APTT, activated partial thromboplastin time.
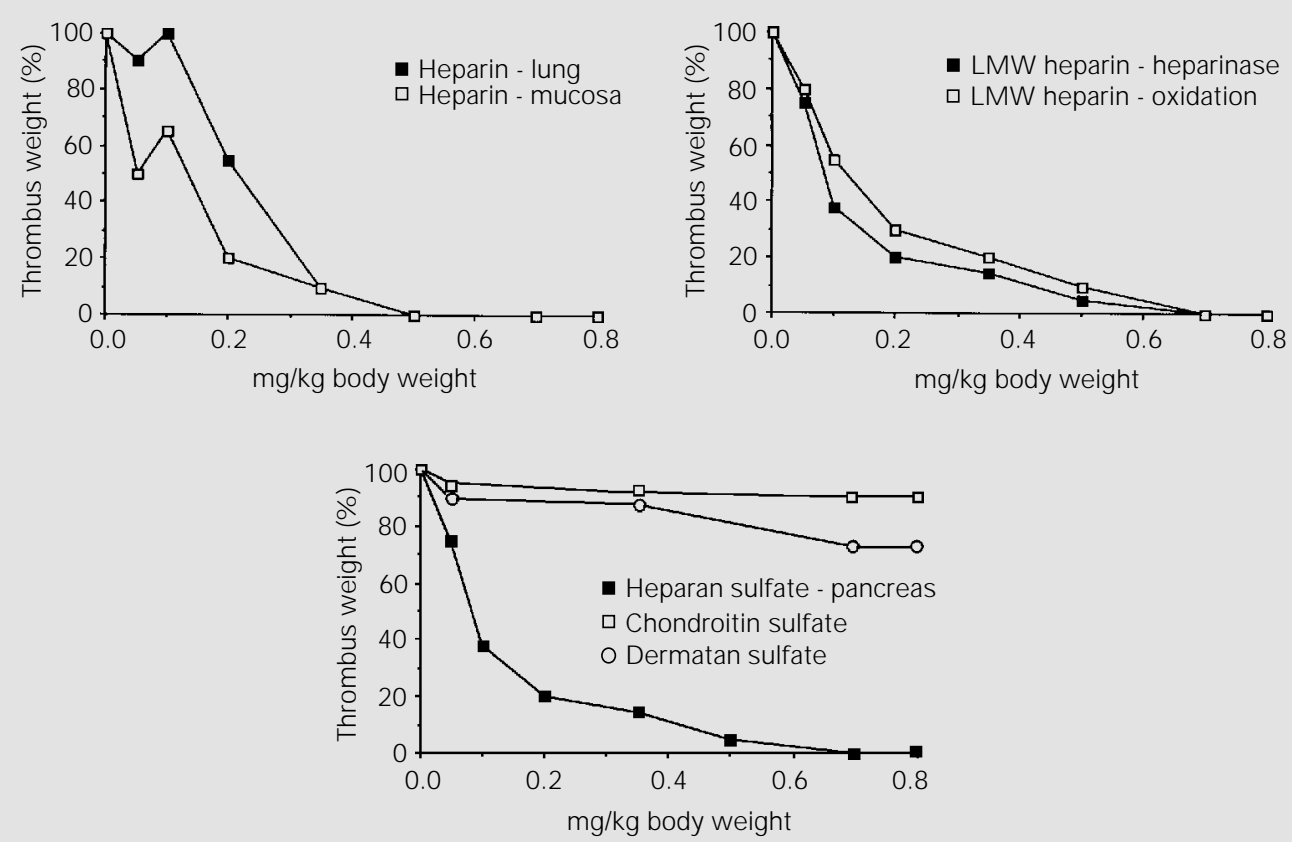

Heparin

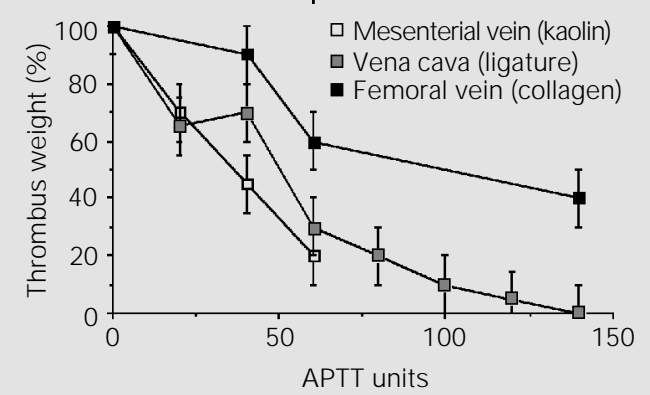

LMW heparin

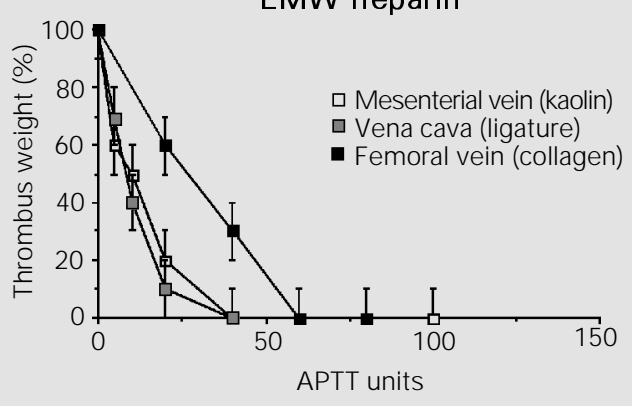

Table 1. In vitro anticoagulant activities and in vivo antithrombotic activities of heparins and low molecular weight (LMW) heparins.

\begin{tabular}{|c|c|c|c|c|c|c|}
\hline \multirow[t]{3}{*}{ Sample } & \multirow[t]{3}{*}{ MM (kDa) } & \multicolumn{4}{|c|}{ In vitro (U/mg) } & \multirow{3}{*}{$\begin{array}{c}\text { In vivo } \\
\text { antithrombotic } \\
\text { activity }\end{array}$} \\
\hline & & \multirow[t]{2}{*}{ USP } & \multirow[t]{2}{*}{ APTT } & \multicolumn{2}{|c|}{ Anti-Xa } & \\
\hline & & & & Chr. & Y.W. & \\
\hline \multicolumn{7}{|l|}{ Heparin } \\
\hline Intestine & 15.1 & 140 & 135 & 106 & 69 & 176 \\
\hline Lung & 9.6 & 130 & 74 & 90 & 60 & 96 \\
\hline Pancreas & 9.6 & 140 & 154 & 129 & 68 & 84 \\
\hline \multicolumn{7}{|l|}{ LMW heparin } \\
\hline Oxidation & 4.5 & 48 & 37 & 87 & 162 & 119 \\
\hline Molecular sieving & 4.6 & 49 & 31 & 100 & 187 & 161 \\
\hline Heparinase & 5.8 & 45 & 22 & 78 & 265 & 146 \\
\hline
\end{tabular}

APTT, activated partial thromboplastin time; Chr., chromogenic assay; Y.W., Yin and Wessler assay; USP, United States Pharmacopea anticoagulant assay; MM, molecular mass. 
A
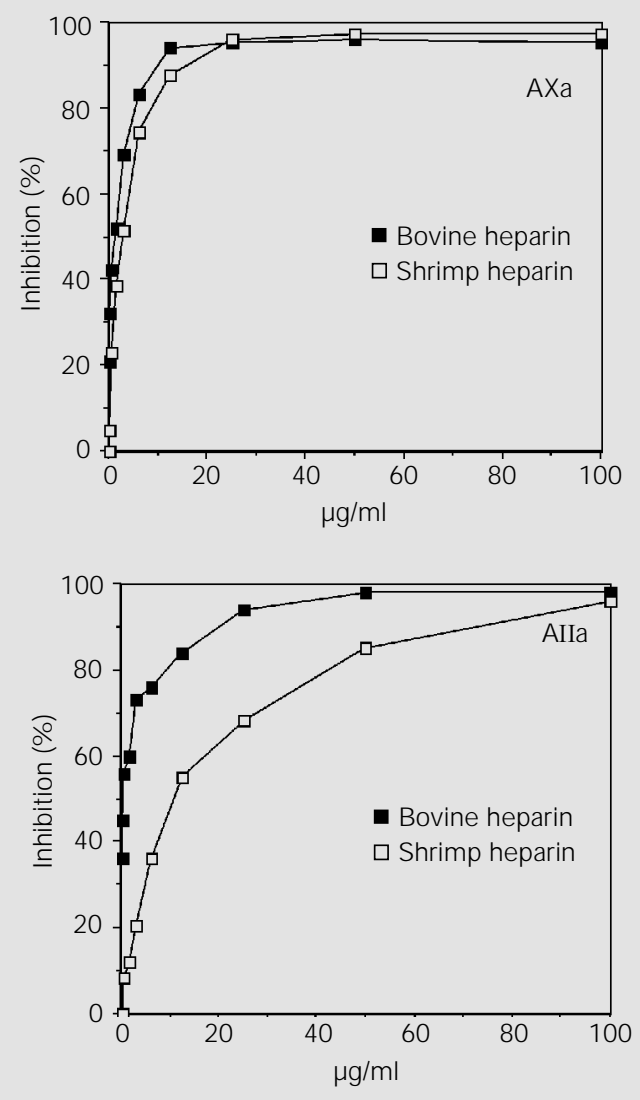

B

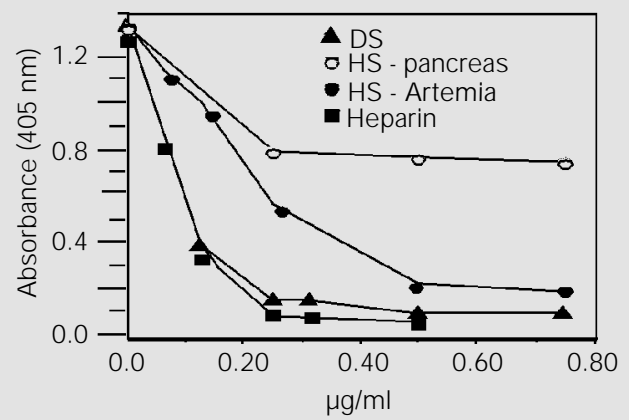

C

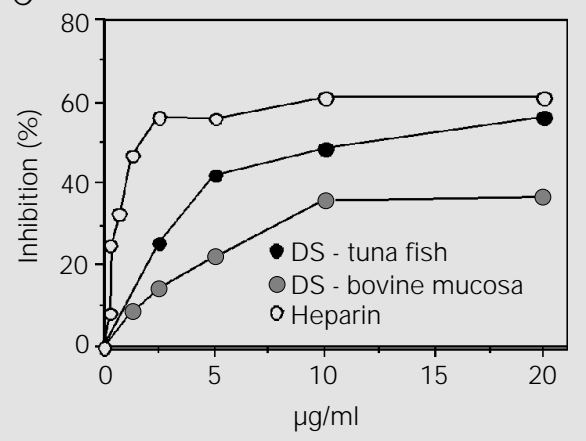

Figure 7. In vitro anticoagulant activities of different heparinoids. A, AXa and Alla activity of shrimp heparin compared to bovine heparin from Ref. 15. B, Heparin cofactor II activity of Artemia franciscana from Ref. 18. C, Heparin cofactor II activity of dermatan sulfate from tuna fish. DS, dermatan sulfate; HS, heparan sulfate.

Table 2. Effect of low molecular weight (LWM) and shrimp heparins on the induction of thrombosis by laser shots.

\begin{tabular}{|c|c|c|c|c|}
\hline \multirow[t]{2}{*}{ Agent } & \multirow[t]{2}{*}{ Dosage (mg/kg) } & \multirow[t]{2}{*}{ Injection route } & \multicolumn{2}{|c|}{ Number of laser shots* } \\
\hline & & & $5 \mathrm{~min}$ & $15 \mathrm{~min}$ \\
\hline Saline Exp. 1 & - & sc & 2 & 3 \\
\hline Saline Exp. 2 & - & sc & 3 & 3 \\
\hline LMW heparin & 1.0 & sc & 7 & 5 \\
\hline LMW heparin & 2.5 & sc & 5 & 3 \\
\hline Shrimp heparin Exp. 1 & 1.0 & sc & 5 & 6 \\
\hline Shrimp heparin Exp. 2 & 1.0 & sc & 7 & 7 \\
\hline LMW heparin & 0.5 & iv & 10 & 7 \\
\hline Shrimp heparin Exp. 1 & 0.25 & iv & 6 & 5 \\
\hline Shrimp heparin Exp. 2 & 0.25 & iv & 5 & 4 \\
\hline Shrimp heparin Exp. 1 & 0.5 & iv & 6 & 6 \\
\hline Shrimp heparin Exp. 2 & 0.5 & iv & 6 & 5 \\
\hline
\end{tabular}

*Number of laser shots needed to produce a thrombus in rabbit peritoneum 5 or 15 min after injection. sc, subcutaneous; iv, intravenous; Exp., experiment. 
Figure 8. In vivo antithrombotic activity of glycosaminoglycans in an arterial model. Data are from Ref. 17. Note: as authors of this paper we have the right to reproduce our previous data in reviews.

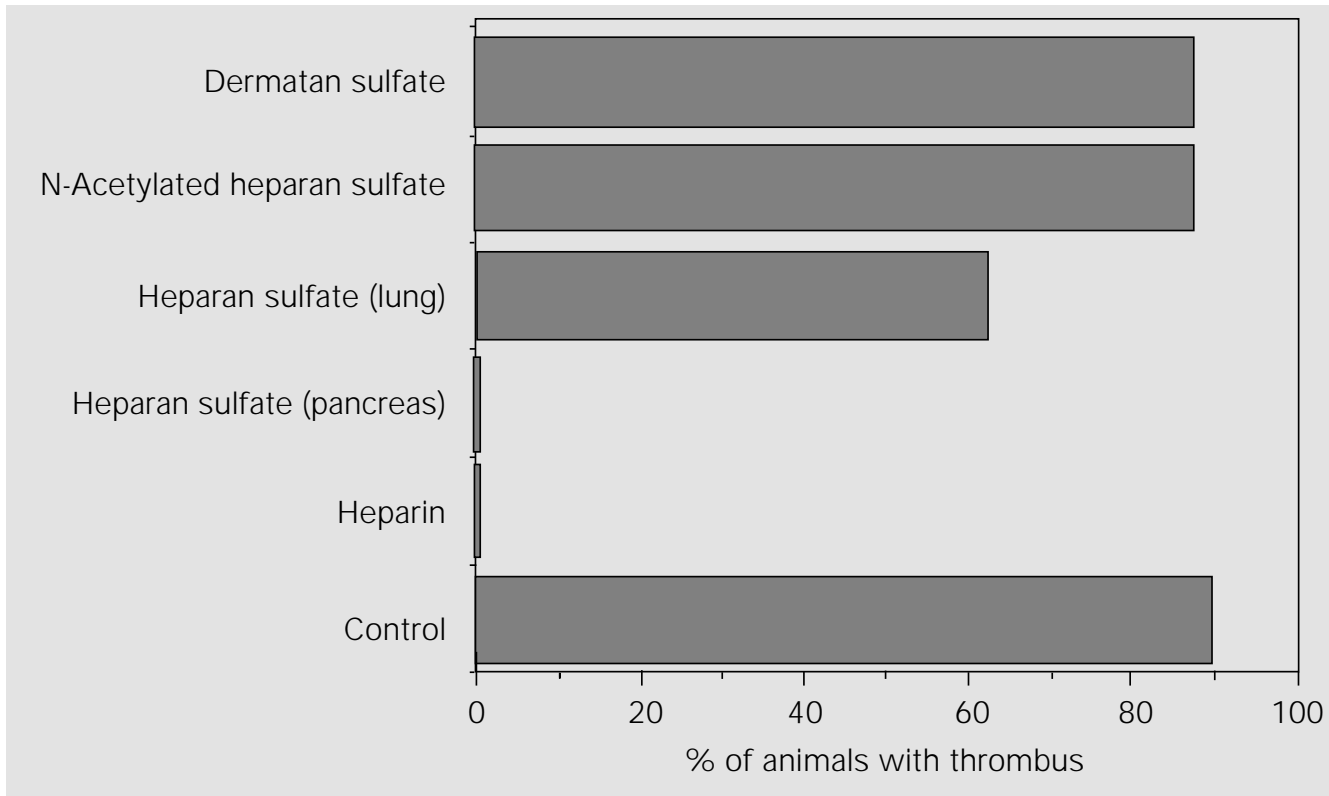

Table 3. Antithrombotic sulfated compounds (approved or under development).

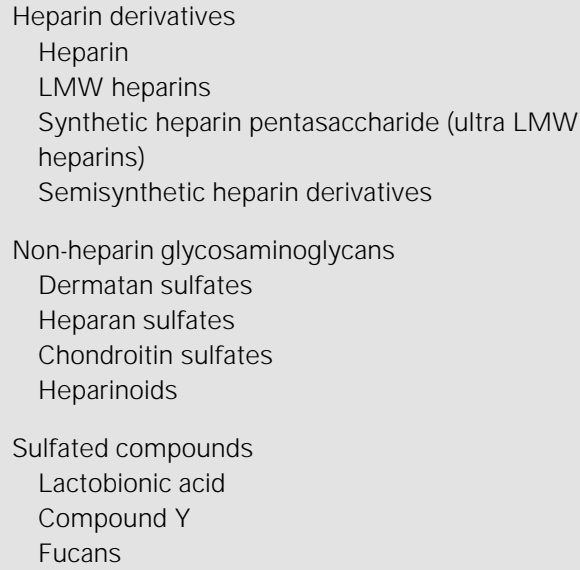

LMW, low molecular weight.

tuna fish skin (also a discard from the food industry) has a potent activity on heparin cofactor II-mediated thrombin inhibition (Figure 7C).

Table 3 summarizes some of the compounds approved or under development as antithrombotic drugs. LMW heparins are widely used and the pharmaceutical industry is now testing a synthetic heparin pentasac- charide in humans. Non-heparin glycosaminoglycans such as heparan and dermatan sulfate are already in clinical trials; highly sulfated chondroitin sulfates have been produced and used topically. Sulfated compounds, such as lactobionic acids, pentosan sulfate and compound Y $(19,20)$ also show antithrombotic activities. Another possible commercial source for antithrombotic compounds is brown seaweed (algae) that contains special sulfated polysaccharides named fucans (21).

\section{Vascular endothelial cell response to antithrombotic agents}

We have discussed so far the site of action of these drugs in the protease network of coagulation. As previously mentioned, the vessel wall is another site of action for antithrombotic compounds. In the eighties Colburn and Buonassisi (22) reported that an endothelial cell line in culture showed blood compatibility, i.e., the surface of these cells had antithrombotic activity. Thus, when the surface of endothelial cells changes, there is a chance of thrombus formation. Among the compounds present on the cell surface 

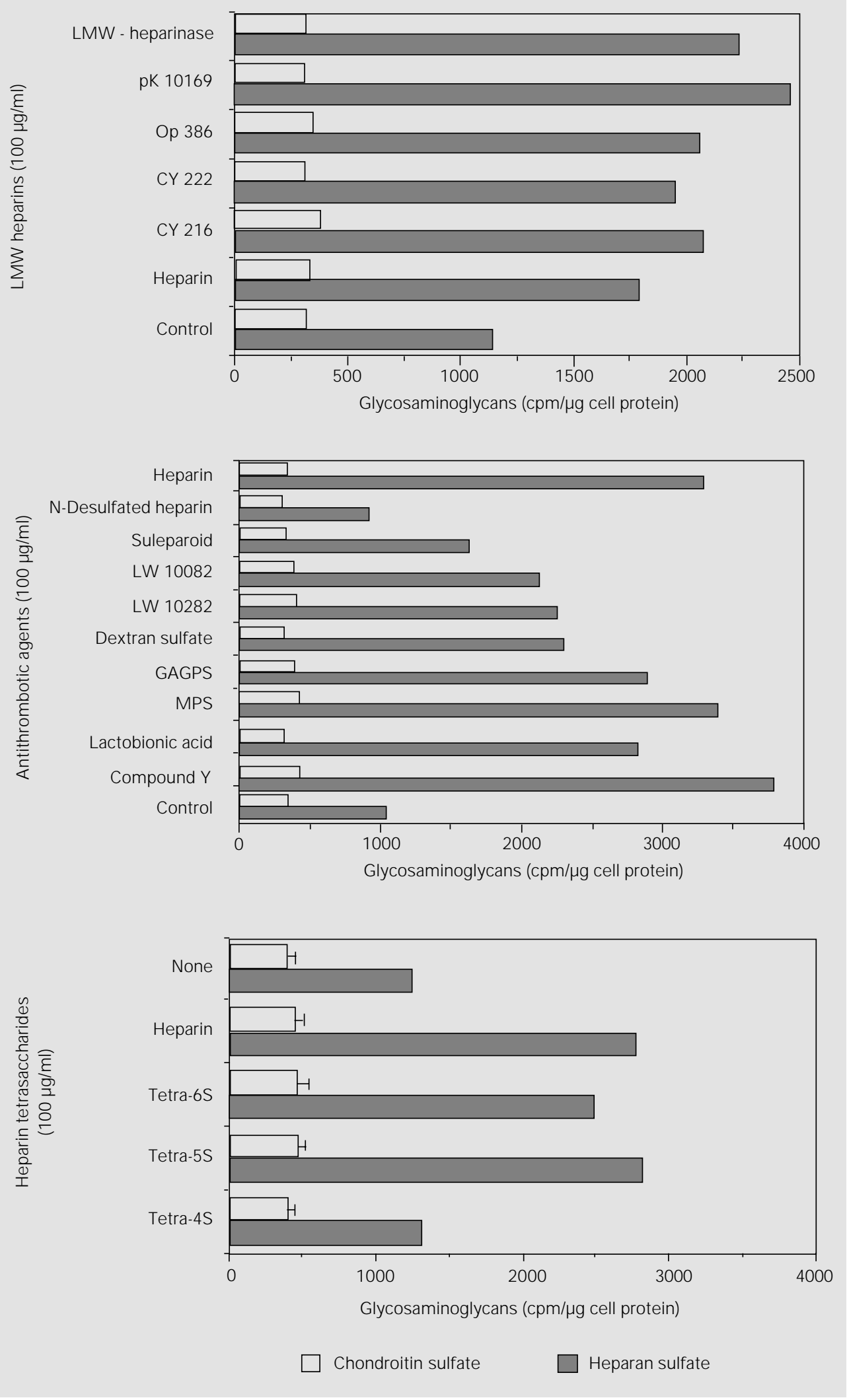

Figure 9. Stimulation of heparan sulfate synthesis in endothelial cells by different antithrombotic agents. GAGPS and MPS: mixture of glycosaminoglycans from Organon; Op 386, CY 222, CY 216, LW 10082, and LW 10282: low molecular weight (LMW) heparins from different pharmaceutical industries; suleparoid: oversulfated chondroitin sulfate; compound Y: cyclic octaphenol-octasulfonic acid; tetra-4S, -5S, and -6S: tetra-, penta- and hexasulfated tetrasaccharides obtained from heparin by heparinase degradation (26). 
and in the extracellular matrix of endothelial cells are heparan sulfate proteoglycans. These heparan sulfates have been shown to possess antithrombotic activity in different models (22). This activity was absent in the heparan sulfate from smooth muscle cells (22).

When heparin is given to a patient, the endothelium is possibly one of the sites of action for the compound. Endothelial cells (rabbit aorta (23) and human umbilical cord (24)) exposed to heparin increase the synthesis of the antithrombotic heparan sulfate present on the cell surface, as well as the one released into the medium (25-27). As shown in Figure 9, this effect is also elicited by LMW heparins (26). When heparin was fragmented with heparinase from Flavobacterium heparinum (28) and the different fragments were also tested as elicitors of the synthesis of endothelial heparan sulfate (26), it was shown that the minimum structural requirement needed to enhance the synthesis of antithrombotic heparan sulfate is the presence of a pentasulfated tetrasaccharide (Figure 9). N-Desulfation of heparin completely abolishes the stimulating activity. Other sulfated compounds, such as lactobionic acids, that consist of two sulfated lactose residues linked by a sequence of 3 to 12 carbons, a cyclic octaphenol-octasulfonic acid (compound Y), dextran sulfate, oversulfated chondroitin sulfates, a fucan from brown seaweed (21) and other compounds that possess antithrombotic activity also increase the synthesis of the endothelial antithrombotic heparan sulfate (Figure 9).

Since an increased synthesis of heparan sulfate chains is observed when the cells are exposed to heparin and other antithrombotic agents, the hypothesis has been raised that the in vivo antithrombotic activity of these compounds is related, at least in part, to the increased production of this peculiar heparan sulfate by endothelial cells. In favor of this hypothesis are the findings that heparintetrasaccharide and compound $\mathrm{Y}$, which are antithrombotic agents in vivo, exhibit a negligible activity in vitro on the serine proteases of the coagulation cascade.

\section{References}

1. Fareed J W, Hoppensteadt D \& Bick RL (2000). An update of heparins at the beginning of the new millenium. Seminars in Thrombosis and Hemostasis, 26: 5-21.

2. Silva ME \& Dietrich CP (1975). Structure of heparin. Characterization of the products formed from heparin by the action of a heparinase and a heparitinase from Flavobacterium heparinum. J ournal of Biological Chemistry, 250: 6841-6846.

3. Dietrich CP, Nader HB \& McDuffie NM (1975). Electrofocusing of heparin. Presence of 21 monomeric and dimeric molecular species in heparin preparations. Anais da Academia Brasileira de Ciências, 47: 301-309.

4. Nader HB, McDuffie NM \& Dietrich CP (1974). Heparin fractionation by electrofocusing: Presence of 21 components of different molecular weights. Biochemical and Biophysical Research Communications, 57: 488-493.

5. McDuffie NM, Nader HB \& Dietrich CP (1975). Electrofocusing of heparin. Frac- tionation of heparin into 21 components distinguishable from other acidic mucopolysaccharides. Biopolymers, 14: 14731486.

6. Bianchini P, Osima B, Parma B, Dietrich CP, Takahashi HK \& Nader HB (1985). Structural studies and in vivo and in vitro pharmacological activities of heparin fractions and fragments prepared by chemical and enzymatic depolymerization. Thrombosis Research, 40: 49-58.

7. Fareed J, J eske W, Hoppensteadt D, Clarizio R \& Walenga J M (1998). Lowmolecular-weight heparins: pharmacologic profile and product differentiation. American J ournal of Cardiology, 82: 3L10L.

8. Fareed J, Hoppensteadt D, J eske W, Clarizio R \& Walenga J M (1998). Low molecular weight heparins: are they different? Canadian J ournal of Cardiology, 14: 28E-34E.

9. Bagge $L$, Wahlberg $T$, Holmer $E$, Tydén $H$, Nyström SO \& Malm T (1994). Low-mo- lecular-weight heparin (Fragmin) versus heparin for anticoagulation during cardiopulmonary bypass in open heart surgery, using a pig model. Blood Coagulation and Fibrinolysis, 5: 265-272.

10. Colwell J r CW (1994). Recent advances in the use of low molecular weight heparins as prophylaxis for deep vein thrombosis. Orthopedics, 17: 5-7.

11. Haas S \& Flosbach CW (1993). Prevention of postoperative thromboembolism with Enoxaparin in general surgery: a German multicenter trial. Seminars in Thrombosis and Hemostasis, 19: 164-173.

12. Hirsh J (1996). Comparison of the relative efficacy and safety of low molecular weight heparin and unfractionated heparin for the treatment of venous thrombosis. Haemostasis, 26: 189-198.

13. Martineau $P \&$ Tawil N (1998). Low-molecular-weight heparins in the treatment of deep-vein thrombosis. Annals of Pharmacotherapy, 32: 588-598.

14. Dietrich CP, Shinjo SK, Moraes FA, Castro 
RAB, Mendes A, Gouvea TC \& Nader HB (1999). Structural features and bleeding activity of commercial LMW-heparins: Neutralization by ATP and protamine. Seminars in Thrombosis and Hemostasis, 25: 43-50.

15. Dietrich CP, Paiva J F, Castro RAB, Chavante SF, J eske W, Fareed J , Gorin PAJ , Mendes A \& Nader HB (1999). Structural features and anticlotting activities of a novel natural low molecular weight heparin from the shrimp Penaeus brasiliensis. Biochimica et Biophysica Acta, 1428: 273283.

16. Bianchini P, Osima B, Parma B, Nader HB \& Dietrich CP (1985). Lack of correlation between in vitro and in vivo antithrombotic activity of heparin fractions and related compounds: Heparan sulfate as an antithrombotic agent in vivo. Thrombosis Research, 40: 597-607.

17. Mattar L, Maffei FHA, Nader HB \& Dietrich CP (1994). Effect of different glycosaminoglycans in a guinea-pig carotid artery thrombosis model. Thrombosis Research, 75: 591-599.

18. Chavante SF, Santos EA, Oliveira FW, Guerrini M, Torri G, Casu B, Dietrich CP \& Nader HB (2000). A novel heparan sulfate with high degree of $\mathrm{N}$-sulfation and high heparin cofactor-II activity from the brine shrimp Artemia franciscana. International J ournal of Biological Macromolecules, 27: 49-57.

19. J eske W, Nelson S, Lee T, Chen J \& Fareed J (1993). Tissue factor pathway inhibitor (TFPI) release induced by a novel sulfonic acid polyphenol (GL522) following IV administration to cynomolgus monkeys. FASEB J ournal, 7: 210 (Abstract).

20. J eske W, Lojewski B \& Fareed J (1992). Biochemical and pharmacologic studies on a novel polysulfonated oral antithrombotic agent (GL-522-Y-1). Blood, 80: 322a (Abstract).

21. Leite $E M L$, Medeiros MGL, Rocha AAO, Farias GGM, Silva LF, Chavante SF, Dietrich CP \& Nader HB (1998). Structure and pharmacological activities of a sulfated glucuronoxylofucan from the algae Spatoglossum xhröederi. Plant Science, 132: 215-228.

22. Colburn $\mathrm{P} \&$ Buonassisi $\vee$ (1982). Anticlotting activity of endothelial cell cultures and heparan sulfate proteoglycans. Biochemical and Biophysical Research Communications, 104: 220-227.

23. Buonassisi $V \&$ Venter J C (1976). Hormone and neurotransmitter receptors in an established vascular endothelial cell line. Proceedings of the National Academy of Sciences, USA, 73: 1612-1616.

24. Takahashi K\& Sawasaki Y (1991). Human endothelial cell line, ECV304, produces pro-urokinase in vitro. In vitro Cellular and Developmental Biology, 27: 766-768.

25. Nader HB, Buonassisi V, Colburn P \& Dietrich CP (1989). Heparin stimulates the synthesis and modifies the sulfation pattern of heparan sulfate proteoglycan from endothelial cells. J ournal of Cellular Physiology, 140: 305-310.
26. Pinhal MAS, Santos IAN, Silva IF, Dietrich CP \& Nader HB (1995). Stimulation of the synthesis of an antithrombotic heparan sulfate from endothelial cells by heparin and its fragments. Thrombosis and Haemostasis, 74: 1169-1174.

27. Pinhal MAS, Walenga JM, J eske W, Hoppensteadt D, Dietrich CP, Fareed J \& Nader HB (1994). Antithrombotic agents stimulate the synthesis and modify the sulfation pattern of a heparan sulfate proteoglycan from endothelial cells. Thrombosis Research, 74: 143-153.

28. Nader HB, Porcionatto MA, Moraes CT \& Dietrich CP (1990). Purification and substrate specificity of heparinase, heparitinase I and heparitinase II from Flavobacterium heparinum. J ournal of Biological Chemistry, 265: 6807-6813.

29. Bianchini P, Osima B, Parma B, Nader HB $\&$ Dietrich CP (1982). Pharmacological activities of heparins obtained from different tissues: Enrichment of heparin fractions with high lipoprotein lipase, antihemolytic and anticoagulant activities by molecular sieving and antithrombin III affinity chromatography. J ournal of Pharmacology and Experimental Therapeutics, 220: 406-410.

30. Lasker SE \& Stivala SS (1966). Physicochemical studies of fractionated bovine heparin. I. Some dilute solution properties. Archives of Biochemistry and Biophysics, 115: 360-372. 